\title{
Hadley Circulation in the Present and Future Climate Simulations of the K-ACE Model
}

\author{
lje Hur $^{1} \cdot$ Minju Kim ${ }^{1} \cdot$ Kyungmin Kwak $^{2} \cdot$ Hyun Min Sung ${ }^{3} \cdot$ Young-Hwa Byun $^{3} \cdot$ Hajoon Song $^{2} \cdot$ Changhyun Yoo $^{1}(\mathbb{C}$
}

Received: 10 May 2021 / Revised: 21 August 2021 / Accepted: 26 August 2021 / Published online: 4 October 2021

(c) The Author(s) 2021

\begin{abstract}
Hadley circulation (HC) is a planetary-scale overturning circulation in the tropics that transports momentum, heat, and moisture poleward. In this study, we evaluate the strength and extent of the $\mathrm{HC}$ in the historical and future climate simulations of the Korean Meteorological Administration (KMA) Advanced Community Earth system model (K-ACE), which was recently developed by the National Institute of Meteorological Sciences of Korea. Compared with a reanalysis product, the overall structure of the $\mathrm{HC}$ is reasonably reproduced by the K-ACE. At the same time, it is also found that the Northern Hemisphere $\mathrm{HC}$ in the K-ACE is shifted southward by a few degrees, while the strength of the Southern Hemisphere (SH) HC is underrepresented by approximately $20 \%$. These biases in the strength and extent of the $\mathrm{HC}$ can be explained by biases in the eddy momentum flux and precipitation in the tropics. In the future climate simulations under the Shared Socioeconomic Pathway 5-Representative Concentration Pathway 8.5 scenario, the HCs in the K-ACE show a weakening and widening trend in both hemispheres, which is consistent with the projections of many Coupled Model Intercomparison Project Phase 6 models. A notable feature of the K-ACE is the widening of the $\mathrm{SH} \mathrm{HC}$, which takes place at a rate that is about double the multi-model mean. Climate models that share the component models with the K-ACE, such as UKESM, HadGEM3-GC31-LL, and ACCESS-CM2/ESM1, also show enhanced poleward expansion of the HC in the SH. This strong expansion is shown to be dominated by the expansion of the regional HC over the Pacific.
\end{abstract}

Keywords K-ACE model $\cdot$ Hadley circulation $\cdot$ CMIP $\cdot$ Historical simulation $\cdot$ Scenario simulation

\section{Introduction}

Hadley circulation (HC) refers to a thermally direct, meridional overturning circulation in the tropics. The ascending motion of the $\mathrm{HC}$ at the equator is associated with the convection of warm and moist air, which leads to the formation of clouds and precipitation. The descending motion of the $\mathrm{HC}$ in the subtropics is accompanied by the subsidence of relatively cool and dry air. As a result, the

\section{Responsible Editor: Seok-Woo Son}

Changhyun Yoo

cyoo@ewha.ac.kr

1 Department of Climate and Energy Systems Engineering, Ewha Womans University, 52 Ewhayeodae-gil, 03760 Seoul, South Korea

2 Department of Atmospheric Sciences, Yonsei University, Seoul, Korea

3 Innovative Meteorological Research Department, National Institute of Meteorological Sciences, Seogwipo, Jeju, Korea
$\mathrm{HC}$ has a great influence on the global hydrological cycle, energy balance, and the circulation of the atmosphere. Furthermore, regional climates, such as monsoon climates, and sea surface temperatures are also known to be strongly connected to the strength and meridional extent of the HC (Bindoff et al. 2013; Zhou et al. 2020). For example, when the $\mathrm{HC}$ is widened, precipitation over the southeast Australia decreases, and the dry season of the southern Amazon gets enhanced (Cai and Cowan 2013; Fu et al. 2013).

For the width of the HC, many climate models project the widening in response to anthropogenic forcing, including increases in greenhouse gas concentration (Chemke and Polvani 2019; $\mathrm{Hu}$ et al. 2018). When the carbon dioxide concentration is quadrupled (i.e., the $4 \times \mathrm{CO}_{2}$ forcing simulations), many models in the Coupled Model Intercomparison Project Phase 6 (CMIP6) show expansions of the $\mathrm{HC}$ by a few degrees over decades, while the degree of expansion varies between models, hemispheres, and seasons (Grise and Davis 2020). The same conclusion has previously been drawn from CMIP Phase 5 (CMIP5) model 
simulations (Tao et al. 2016), despite some differences in the extent of widening being greater for the CMIP6 models in the Northern Hemisphere $(\mathrm{NH})$, possibly because of the differences in external forcings, such as solar/volcanic forcing, anthropogenic aerosols, and ozone concentrations (Allen and Ajoku 2016; Grise and Davis 2020). Interestingly, the widening of the $\mathrm{HC}$ of about $0.2^{\circ}$ per decade in both hemispheres has been observed since the late 1970s $(\mathrm{Hu}$ and Fu 2007; Nguyen et al. 2013; Rollings and Merlis 2021; Staten et al. 2019). This trend is due to enhanced static stability in the tropics (e.g., Lu et al. 2007) and stratospheric ozone depletion in the Southern Hemisphere ( $\mathrm{SH}$; Son et al. 2010; Kim et al. 2017), as well as the role of natural variability (Grise et al. 2019).

For the strength of the HC, weakening is projected to be another important feature of the $\mathrm{HC}$ in the future climate (Chemke and Polvani 2019; Hu et al. 2018; Liu et al. 2012). According to Chemke and Polvani (2019), CMIP5 models, forced by climate forcings (e.g., greenhouse gas concentrations and aerosols) of the Representative Concentration Pathway 8.5 scenario, show a statistical reduction in HC strength of less than $0.1 \%$ per year, i.e., approximately $-6.8 \times 10^{7} \mathrm{~kg} \mathrm{~s}^{-1} \mathrm{yr}^{-1}$ during 1979-2017 (Fig. 1 in Chemke and Polvani 2019). A similar trend has been obtained in their study from large ensemble simulations of the Community Earth System Model, while observations in recent decades show a trend with the opposite sign, that is, a strengthening of the HC. This discrepancy in $\mathrm{HC}$ between the climate models and observations may lead to inaccurate projections of future climates because of the immense role of the $\mathrm{HC}$ in global energy, momentum, and hydrological cycles. Therefore, it is important to understand how the HCs are represented in climate models.

The National Institute of Meteorological Sciences/Korea Meteorological Administration (NIMS/KMA) has recently developed the KMA Advanced Community Earth system model (K-ACE) by collaboration with the UK Met Office. The K-ACE is a coupled atmosphere-ocean-land-sea ice model that is designed to provide multi-decadal climate simulations as for other CMIP6 models. A detailed description of the K-ACE is presented in Lee et al. (2020), such as the model components and coupling techniques. A brief introduction to the K-ACE is given in the following. The K-ACE consists of the Unified Model Global Atmosphere 7.1 (Walters et al. 2019), the Modular Ocean Model (MOM; Griffies et al. 2004), the Joint UK Land Environment Simulator (Best et al. 2011), and the Los Alamos Sea Ice Model (Hunke et al. 2015) through the coupler OASIS3-MCT. The key difference between the K-ACE and the UK Earth System Model is the ocean component model and the representation of aerosols, among many others. Sung et al. (2021) documented the performance of the K-ACE for climate mean states (e.g., surface temperature, precipitation, and sea ice extent) and climate variability (e.g., Northern and Southern
Annular Modes) in the present and future climate. However, it has not been reported whether the $\mathrm{HC}$ is reasonably represented in the model or how it is projected to the changes under the future scenarios.

Therefore, the objective of the present study is to evaluate the $\mathrm{HC}$ in historical and future climate scenario simulations using the K-ACE. For the historical simulation, the annual mean and seasonal means of the $\mathrm{HC}$ are compared against those from the reanalysis. Possible causes of the model bias are examined in terms of the diagnostic equation of the zonal mean meridional streamfunction. For the future projection, the K-ACE simulation forced by the Shared Socioeconomic Pathway 5-Representative Concentration Pathway 8.5 (SSP58.5) scenario is compared with corresponding CMIP6 model simulations in terms of the extent and strength of the HC.

The rest of this paper is organized as follows. Section 2 describes the observational and model simulation data and analysis methods. Sections 3 and 4 present evaluations of the historical and future scenario simulations of the K-ACE, respectively. Discussion and Conclusions and discussion are provided in Section 5.

\section{Data and Methods}

\subsection{Data}

We employ three ensemble members of the historical (years 1850-2014) and the SSP5-8.5 scenario (years 2015-2100) simulations of the K-ACE. Both simulations are conducted following the experimental design of the CMIP6 (O'Neill et al. 2016), which is described in detail by Sung et al. (2021). To diagnose the HC, monthly fields of meridional wind, surface pressure, and precipitation rate are analyzed. Also, daily fields of horizontal wind and temperature are used to measure the eddy fluxes. The horizontal resolution of the data is $1.875^{\circ}$ longitude $\times 1.25^{\circ}$ latitude, however, for comparison with the reanalysis, the resolution of the data is reduced to $2.5^{\circ}$ longitude $\times 2.5^{\circ}$ latitude through bilinear interpolation. Vertically, the monthly and daily data have 19 and 8 levels, respectively, up to the 50-hPa pressure level.

Furthermore, to provide a comparison with other climate models participating in the CMIP6, we additionally analyze the nine climate models listed in Table 1 . The models were chosen simply because they had data available from the early phase of the present study. For the intercomparison between the models and the reanalysis, bilinear horizontal interpolation is applied to conform the grid to a resolution of $2.5^{\circ}$ longitude $\times 2.5^{\circ}$ latitude resolution. For the computation of the HC extent, the model data were used at their original resolution for better accuracy. Regional Hadley cells of the 
Table 1 The global climate models and the spatial resolution used in this study. One ensemble member, which is arbitrarily selected, is used for each model

\begin{tabular}{ll}
\hline CMIP6 Model & $\begin{array}{l}\text { Horizontal Resolu- } \\
\text { tion }\left({ }^{\circ} \text { lon } \times{ }^{\circ} \text { lat }\right)\end{array}$ \\
\hline ACCESS-CM2 & $1.875^{\circ} \times 1.25^{\circ}$ \\
ACCESS-ESM1 & $1.875^{\circ} \times 1.25^{\circ}$ \\
CanESM5 & $2.8125^{\circ} \times 2.7906^{\circ}$ \\
FGOALS-g3 & $2.25^{\circ} \times 2.0^{\circ}$ \\
HadGEM3-GC31-LL & $1.875^{\circ} \times 1.25^{\circ}$ \\
IPSL-CM6A-LR & $2.5^{\circ} \times 1.2676^{\circ}$ \\
MIROC6 & $1.40625^{\circ} \times 1.40625^{\circ}$ \\
MRI-ESM2-0 & $1.125^{\circ} \times 1.125^{\circ}$ \\
UKESM1-0-LL & $1.875^{\circ} \times 1.25^{\circ}$ \\
\hline
\end{tabular}

CMIP6 are presented at $1.875^{\circ}$ longitude $\times 1.25^{\circ}$ latitude to match that of the K-ACE.

We use the European Centre for Medium-range Weather Forecasts (ECMWF) interim reanalysis data (ERAInterim; Dee et al. 2011). As for the model simulations, monthly variables are taken for 1979-2014. It should be noted that the period of the ERA-interim is much shorter than that of the historical run, and therefore, we match the time length of the data when the data are compared. The horizontal resolution of the ERA-interim is also set to $2.5^{\circ}$ longitude $\times 2.5^{\circ}$ latitude, and 19 and 8 vertical levels out of 37 vertical levels are taken to match that of the monthly and daily model simulations, respectively.

\subsection{Definition of the HC}

The HC is defined as the zonal mean meridional streamfunction $(\Psi)$ :

$\Psi(p, \phi)=\frac{2 \pi a \cos (\phi)}{g} \int_{p}^{p s} \bar{v}(p, \phi) d p$,

where $\phi$ is the latitude, $p$ is the pressure, $p_{S}$ is the surface pressure, $a$ is the radius of the earth, $g$ is the gravitational acceleration, and $v$ is the meridional wind. Here, the overbar represents the zonal mean. The strength and extent of the $\mathrm{HC}$ are quantified by the cross-section of the $\Psi$ at $500 \mathrm{hPa}$ $\left(\Psi_{500}\right)$; that is, the strengths of the $\mathrm{NH}(\mathrm{SH}) \mathrm{HCs}$ are defined by the maximum (minimum) value of $\Psi_{500}$ over the latitudes between $15^{\circ} \mathrm{S}-30^{\circ} \mathrm{N}\left(15^{\circ} \mathrm{N}-30^{\circ} \mathrm{S}\right)$. The extent of the $\mathrm{NH}$ (SH) HC is defined by the latitude of sign reversal in $\Psi_{500}$ over the latitudes $20^{\circ} \mathrm{N}-50^{\circ} \mathrm{N}\left(20^{\circ} \mathrm{S}-50^{\circ} \mathrm{S}\right)$.
For the regional definition of the HC, we employ the meridional streamfunction of the divergent horizontal wind ( $\Psi_{d}$; Schwendike et al. 2014):

$\Psi_{d}(p, \phi, \lambda)=\frac{2 \pi a \cos (\phi)}{g} \int_{p}^{p s} v_{d}(p, \phi, \lambda) d p$,

where $\lambda$ is the longitude. The underlying assumption for this regional $\mathrm{HC}$ definition is that the vertical motion in the tropical atmosphere can be decomposed into a zonal Walker circulation component and a meridional $\mathrm{HC}$ component.

\subsection{Diagnostic Equation for the HC}

To examine the cause of model bias, we examine the terms in the diagnostic equation of the zonal mean meridional streamfunction, which can be obtained through the quasigeostrophy assumption (Chapter 10 of Holton and Hakim 2013):

$\frac{\partial^{2} \bar{\Psi}}{\partial y^{2}}+\frac{f_{0}^{2}}{N^{2}} \rho_{0} \frac{\partial}{\partial z}\left(\frac{1}{\rho_{0}} \frac{\partial \bar{\Psi}}{\partial z}\right)=\frac{\rho_{0}}{N^{2}}\left[\frac{\partial}{\partial y}\left(\frac{\kappa \bar{J}}{H}-\frac{R}{H} \frac{\partial}{\partial y} \overline{v^{\prime} T^{\prime}}\right)-f_{0}\left(\frac{\partial^{2}}{\partial z \partial y} \overline{u^{\prime} v^{\prime}}-\frac{\partial \overline{\mathrm{X}}}{\partial z}\right)\right]$

where the prime denotes the deviation from the zonal mean. This equation accounts for the fact that the zonal mean meridional circulation $(\bar{\Psi})$ is determined by the zonally averaged diabatic heating $(\bar{J})$, the eddy heat flux $\left(\overline{v^{\prime} T^{\prime}}\right)$, and the eddy momentum flux $\left(\overline{u^{\prime} v^{\prime}}\right)$, while the zonal drag force $(\bar{X})$ is neglected. Because of the elliptic operator to the streamfunction in the left-hand side, one may expect that $\bar{\Psi}>0$ over the regions where the diabatic heating decreases poleward, the eddy heat flux is minimum, and the eddy vorticity flux decreases with height. As a representation of the diabatic heating, the precipitation rate will be examined.

\section{The Hadley Circulation in the Historical Simulation}

\subsection{Climatology}

Starting with the historical simulation, we first examine whether the time mean HCs are well represented in the K-ACE. Note that for comparisons with the ERA-Interim, we use the ensemble mean of the simulations for the period between 1979-2014 in this section. When averaged for all seasons (ANN; Fig. 1a), the upward branch of the HCs is located near $5^{\circ} \mathrm{N}$, while downward branches are located at approximately $30^{\circ} \mathrm{S}$ and $30^{\circ} \mathrm{N}$. The maxima of the HCs are reached near $\pm 10^{11} \mathrm{~kg} \mathrm{~s}^{-1}$ at pressure levels between 500 and $700 \mathrm{hPa}$. For December-February (DJF), the streamfunction exhibits a strengthened $\mathrm{NH}$ winter $\mathrm{HC}$ between $10^{\circ} \mathrm{S}-30^{\circ} \mathrm{N}$, 

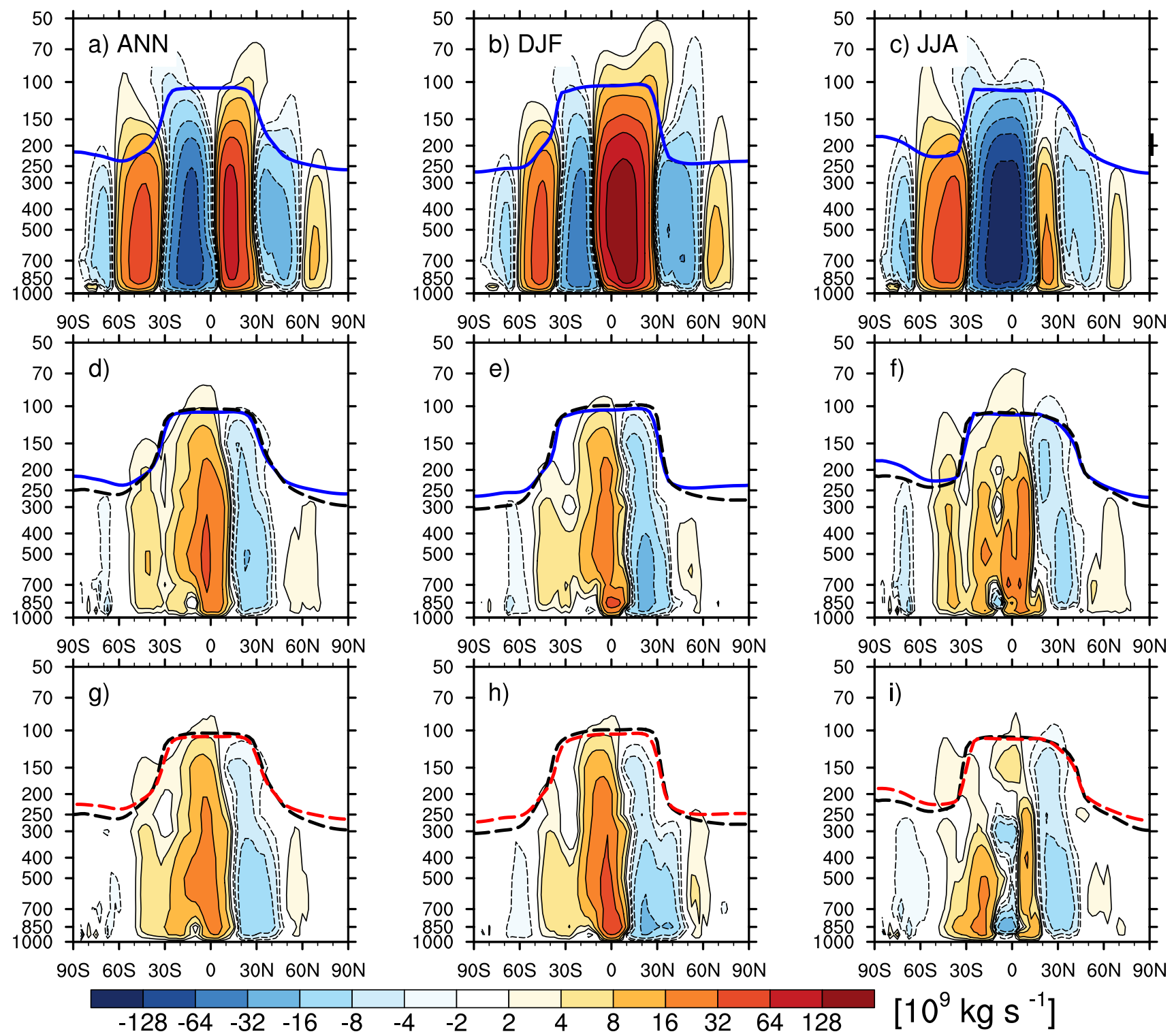

Fig. 1 The zonal mean meridional streamfunction $\bar{\Psi}$ of the historical simulation of the K-ACE are time-averaged during years 1979-2014 for (a) ANN, (b) DJF, and (c) JJA. The values obtained by subtracting the corresponding means of the ERA-interim from those of the $\mathrm{K}-\mathrm{ACE}$ are shown in the middle row $(\mathbf{d}-\mathbf{f})$ and subtracting the means

with a maximum value exceeding $2.1 \times 10^{11} \mathrm{~kg} \mathrm{~s}^{-1}$ (Fig. 1b). For June-August (JJA), the SH HC extends up to $15^{\circ} \mathrm{N}$, and its strength is about $-2.2 \times 10^{11} \mathrm{~kg} \mathrm{~s}^{-1}$ (Fig. 1c). Vertically, the $\mathrm{HCs}$ are roughly bounded by the tropopause height (solid blue curves in Fig. 1), which is determined by World Meteorological Organization (WMO) definition as the lowest level at which the lapse rate decreases to $2 \mathrm{~K} \mathrm{~km}^{-1}$ or less. As such, the location, extent, and strength of the $\mathrm{HC}$ match reasonably well with the reanalysis, with clear hemispheric symmetry and asymmetry for the annual and seasonal means, respectively (Dima and Wallace 2003). of ERA-interim from those of the CMIP6 are in the bottom $(\mathbf{g}-\mathbf{i})$. The unit for the streamfunction is $10^{9} \mathrm{~kg} \mathrm{~s}^{-1}$. Superposed are the tropopause heights according to the WMO definition for the K-ACE (solid blue curve), for the ERA-interim (dashed black curve) and the CMIP6 (red dashed curve) of the corresponding seasons

To elaborate the bias of the HCs in the K-ACE, we take the time mean of the K-ACE minus that from the ERA-Interim. The difference for all seasons exhibits in general positive and negative anomalies in the tropics of the $\mathrm{SH}$ and $\mathrm{NH}$, respectively. This indicates that the strength of both $\mathrm{HCs}$ in the $\mathrm{NH}$ and $\mathrm{SH}$ are underestimated, although it is more obvious for the SH HC (Fig. 1d). For the extent, the positive anomaly, centered at the equator, suggests that the upward branch of the HCs is shifted southward. The negative anomaly, near $25^{\circ} \mathrm{N}$, indicates that the northward extent of the $\mathrm{NH}$ HC is reduced. These biases in the strength and extent can be clearly seen 


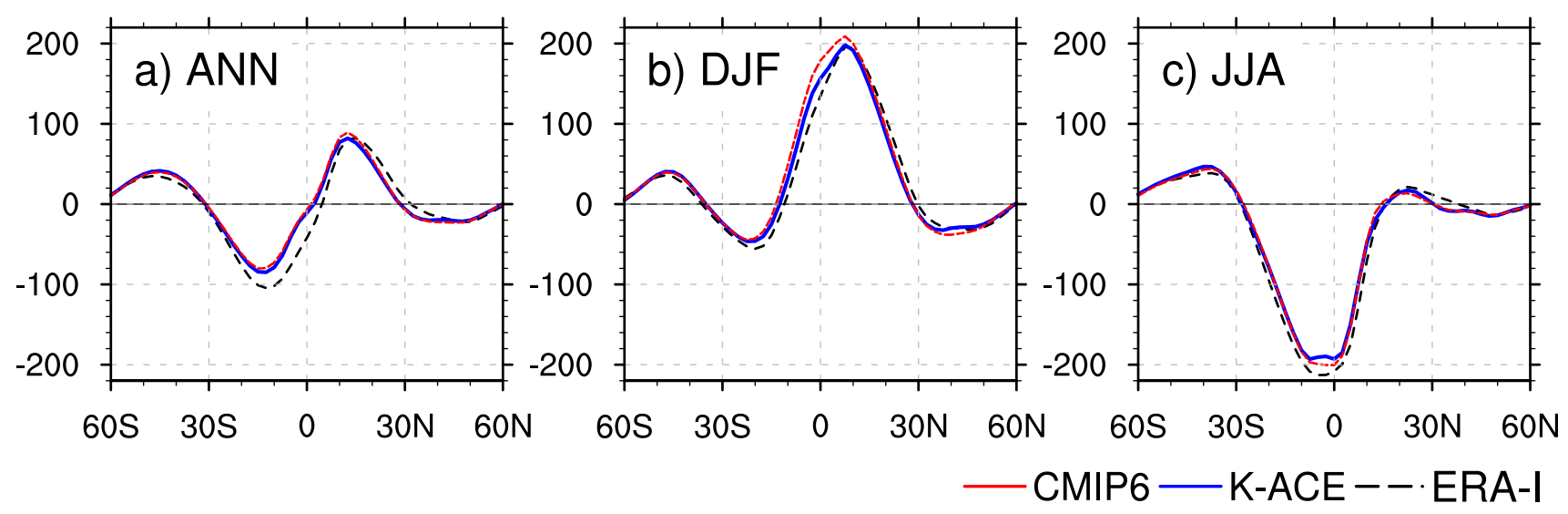

Fig. 2 The zonal mean meridional streamfunction $\bar{\Psi}$ time-averaged as for Fig. 1, except that the cross-section at $500 \mathrm{hPa}$ is shown. The time-averaging is done for (a) ANN, (b) DJF, and (c) JJA. The

from the cross-section at $500 \mathrm{hPa}$ pressure level (Fig. 2a). The SH HC of the K-ACE (solid blue curve in Fig. 2a), which has strength of about $-8.49 \times 10^{10} \mathrm{~kg} \mathrm{~s}^{-1}$, is underestimated by up to approximately $20 \%$ compared to that of the ERA-interim (dashed black curve in Fig. 2a), of which strength is about $-10.45 \times 10^{10} \mathrm{~kg} \mathrm{~s}^{-1}$. We also find that both the southern and northern edges of the NH HC are shifted southward by 1.4 and 1.6 degrees, respectively.

The biases in the annual mean HCs can be accounted for by the biases in the seasonal mean HCs (Figs. 1e, f and $2 b$, c). The underestimation of the strength of the SH HC takes place primarily during JJA, particularly between $10^{\circ} \mathrm{S}-0^{\circ}$ (Figs. 1f and 2c), although a weakened cell can also be found during DJF near $20^{\circ} \mathrm{S}$ (Figs. 1e and $2 \mathrm{~b}$ ). The JJA zonal mean streamfunctions of the K-ACE and ERA-Interim cross the zero line at $28.2^{\circ} \mathrm{S}$ and $28.8^{\circ} \mathrm{S}$, respectively (Fig. 2c), indicating $0.6^{\circ}$ equatorward bias. During DJF, however, the extent of the K-ACE is $28.1^{\circ} \mathrm{N}$, which is substantially located south than that of the ERA-Interim $\left(29.7^{\circ} \mathrm{N}\right)$, showing $1.6^{\circ}$ bias (Fig. 2b). The underestimation of the strength of the SH HC takes place primarily during JJA, particularly between $10^{\circ} \mathrm{S}-0^{\circ}$ (Figs. 1f and 2c), although a weakened cell can also be found during DJF near $20^{\circ} \mathrm{S}$ (Figs. 1e and $2 \mathrm{~b}$ ). We note that the extent and strength bias can be similarly seen from the nine CMIP6 models (Figs. 1g-h and the red lines in Fig. 2).

To examine whether the HC biases are accompanied by biases in the zonal mean temperature, the zonal mean temperature field and its meridional gradient are examined in Fig. 3. Previous studies have found a linear correlation between the poleward extent of the $\mathrm{HC}$ and the meridional gradient of zonal mean temperature over the hemisphere (Choi et al. 2019; Wilcox et al. 2012). However, we find warm and cold biases in the tropical and polar near tropopause, respectively, indicating enhanced meridional unit for the streamfunction is $10^{9} \mathrm{~kg} \mathrm{~s}^{-1}$. The result for the historical K-ACE is shown by the solid blue line, while that for the ERAinterim and CMIP6 are shown by the dashed black and red line, respectively

temperature gradient in the K-ACE. During DJF, for instance, the lower stratosphere in the Arctic shows a strong cold bias, implying steepened meridional temperature gradient. To be consistent with the previous studies, this should have contributed to widened NH HC, which turned out to be the opposite (Fig. 2b). Thus, in the next section, we use the diagnostic equation and examine the role of eddy fluxes and diabatic heating in the $\mathrm{HC}$ formation.

\subsection{Diagnostic Equation}

Having shown the $\mathrm{HC}$ climatology, we now investigate possible causes of the biases through the use of diagnostic Eq. (3). That is, the roles of the time mean eddy momentum flux $\left(\overline{u^{\prime} v^{\prime}}\right)$, eddy heat flux $\left(\overline{v^{\prime} T^{\prime}}\right)$, and diabatic heating $(\bar{J})$ in $\mathrm{HC}$ strength and extent biases are examined.

The time mean eddy momentum and eddy heat fluxes of the K-ACE simulation are presented in Fig. 4 (contours). The difference in the fluxes between the K-ACE and the ERAinterim is shown by shading. For the eddy momentum flux (Fig. 4a-c), the spatial structure and seasonal variation are reasonably captured by the K-ACE with some location and strength biases. The momentum flux is the maximum at the tropopause height with flux convergence between $45^{\circ}-50^{\circ}$ region in both hemispheres (Fig. 4a,b). On the other hand, the eddy heat flux in the SH does not show a realistic structure, although in the $\mathrm{NH}$ it is reasonably centered at $40^{\circ}$ $50^{\circ} \mathrm{N}$ in the lower and the upper troposphere, except for JJA, (Fig. 4d-e). However, the heat flux bias is in a distance from the tropics, which may not have large influence on the HC.

Unlike the eddy heat flux, the momentum flux bias occurs in the tropics and subtropics. Compared to the ERAinterim, the eddy momentum flux is underestimated in the subtropics by approximately $11-16 \%$ in the annual and DJF 

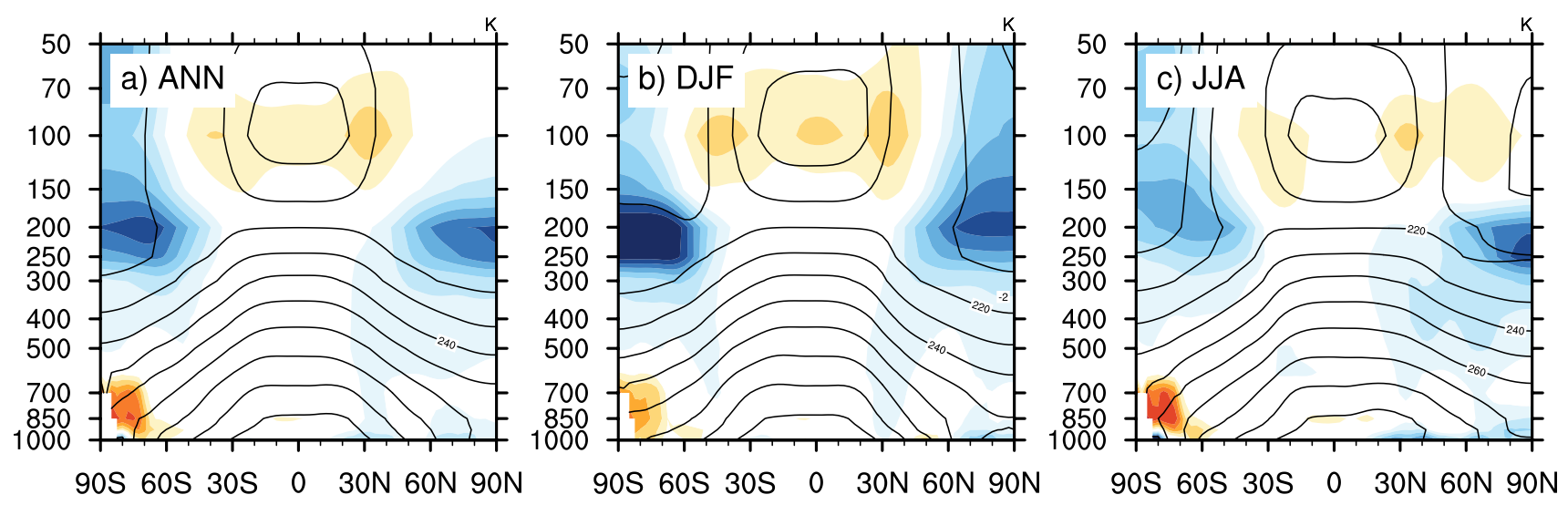

90S 60S 30S $0 \quad 30 \mathrm{~N} 60 \mathrm{~N} 90 \mathrm{~N}$

90S $60 \mathrm{~S} 30 \mathrm{~S} 030 \mathrm{~N} 60 \mathrm{~N} 90 \mathrm{~N}$

$[\mathrm{K}]$

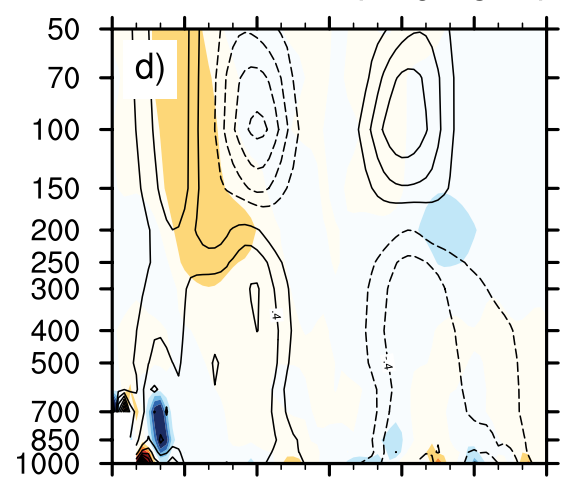

90S 60S 30S $0 \quad 30 \mathrm{~N} 60 \mathrm{~N} 90 \mathrm{~N}$
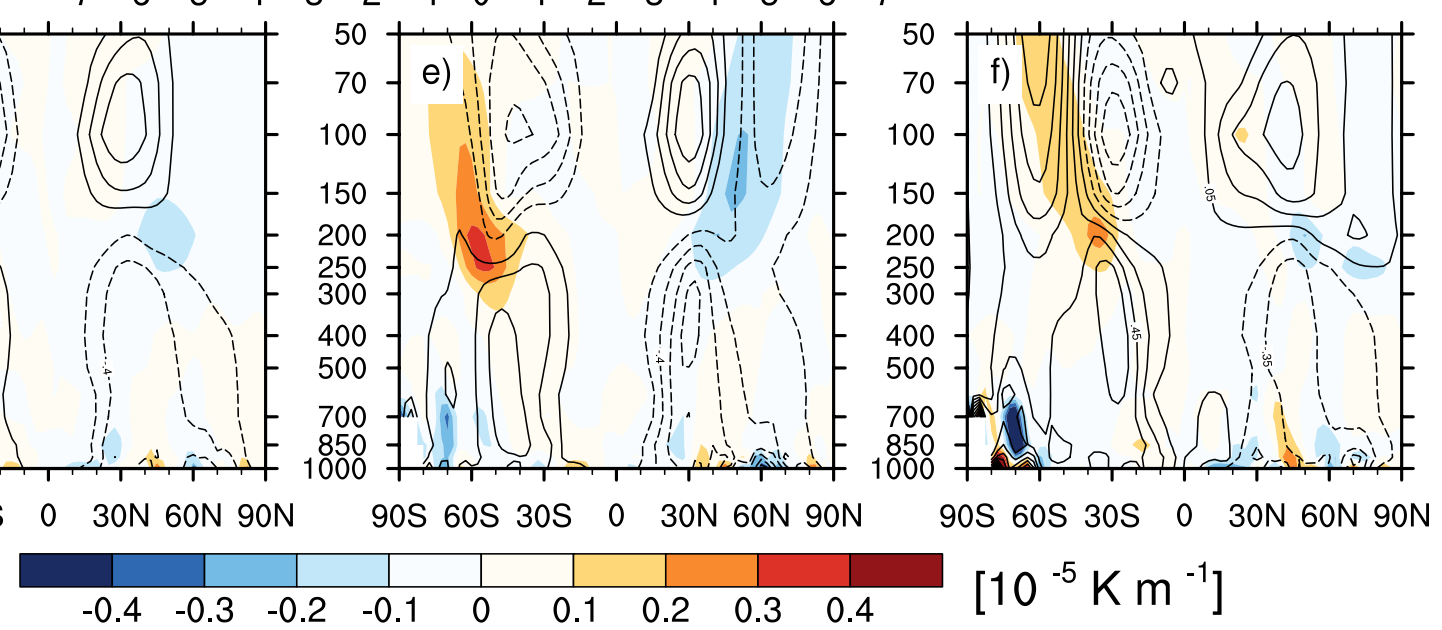

Fig. 3 The time-averaged zonal mean temperature (top) and its meridional gradient (bottom) of the historical K-ACE between 1979-2014 are shown (the contours). The contour of the zonal mean

means (Fig. 4a,b). The weakened eddy momentum flux during DJF, and hence anomalous convergence near $30^{\circ} \mathrm{N}$ (Fig. 4b), contribute to the weakening of the $\mathrm{HC}$ in the K-ACE. During JJA, an underestimation of approximately $10 \%$ can be observed in the tropical momentum convergence (shaded area in Fig. 4c). For the $\mathrm{HC}$ extent bias, the difference fields in the NH for all seasons and DJF (shaded area in Fig. 4a,b) are located to the north of the eddy momentum flux in the ERA-Interim (contours in Fig. 4a, b), implying that their contribution may not dominate the southward shift bias in the HC. Similarly, for JJA, the contribution of the momentum flux to the extent bias of the $\mathrm{HC}$ is weak because the difference field is jointly located with the climatology (Fig. 4c).

To estimate the role of diabatic heating (i.e., $\bar{J}$ in Eq. (3)) in the HC bias, we examine the time mean zonal mean precipitation rate (Fig. 5). The K-ACE captures the precipitation maxima in the intertropical convergence zone (ITCZ) near $5^{\circ} \mathrm{N}$ and in the South Pacific convergence zone (SPCZ) near $10^{\circ} \mathrm{S}$. As has previously been observed for climate temperature and its gradient are $10 \mathrm{~K}$ and $0.2 \mathrm{~K} \mathrm{~m}^{1}$, respectively. The difference between the K-ACE and the ERA-interim is shown by shading

models (e.g., Tian and Dong 2020), the amount of precipitation at the SPCZ (solid blue curve in Fig. 5) is exaggerated in the K-ACE compared to that from the ERA-interim (dashed black curve), while the opposite is true for the ITCZ. For DJF, the mean difference in precipitation rate over the latitudes $15^{\circ} \mathrm{S}-15^{\circ} \mathrm{N}$ between the model simulation and the reanalysis is approximately $-0.20 \mathrm{~mm} \mathrm{day}^{-1}$, which may not result in a net change in the HC strength. However, for JJA, the deficit at the ITCZ is greater than the exaggeration at the SPCZ, which leads to the weakened $\mathrm{HC}$ in the K-ACE. Furthermore, the peaks at ITCZ and SPCZ are shifted equatorward, contributing to the $\mathrm{HC}$ extent bias in the model.

\section{The HC in the SSP5-8.5 Simulation}

To evaluate the future projection of the $\mathrm{HC}$ strength and extent using the K-ACE, we first compare the time-averaged zonal mean streamfunction of the SSP5-8.5 simulation (years 

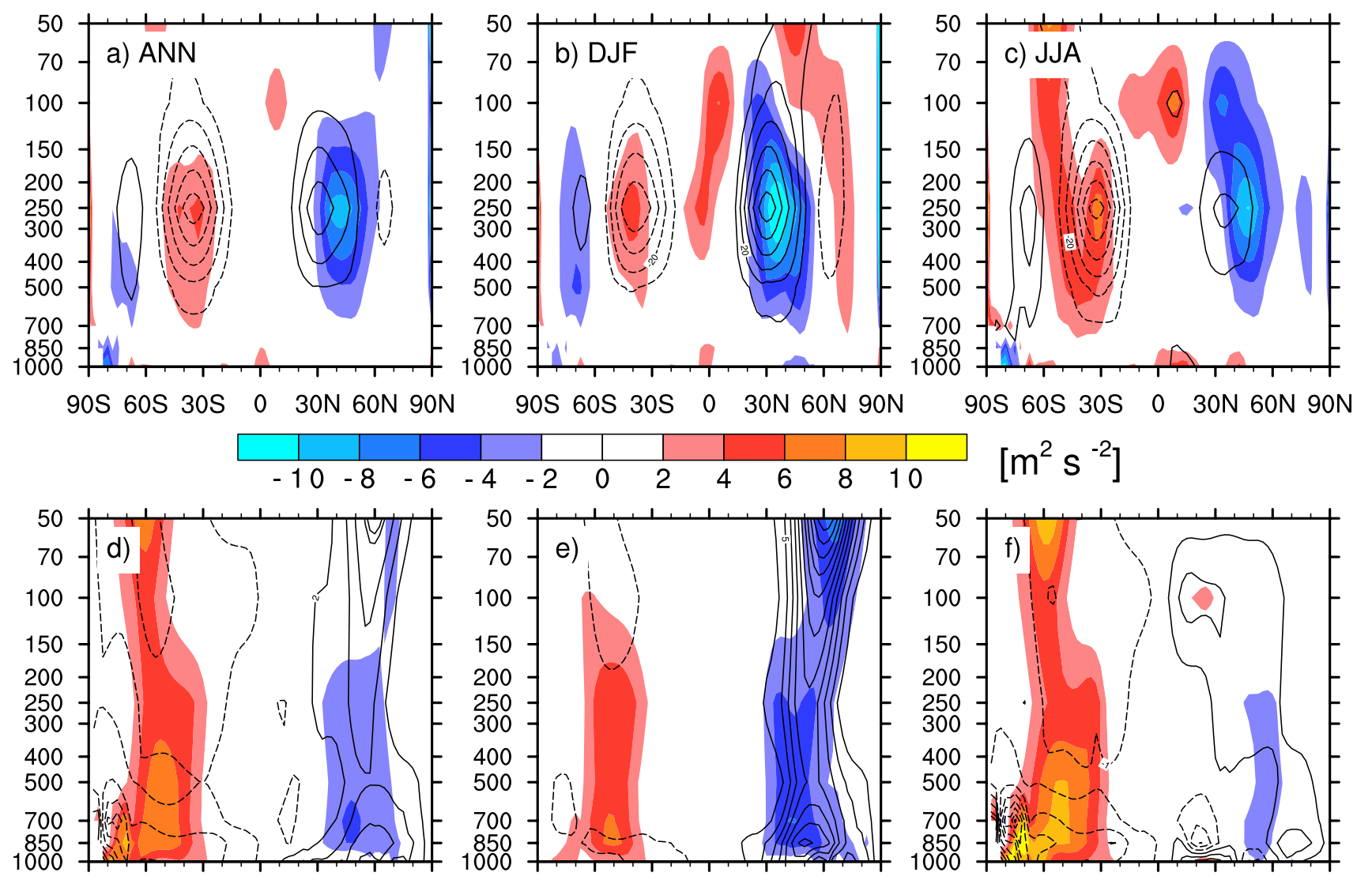

$90 \mathrm{~S} 60 \mathrm{~S} 30 \mathrm{~S} \quad 0 \quad 30 \mathrm{~N} 60 \mathrm{~N} 90 \mathrm{~N}$

90S $60 \mathrm{~S} 30 \mathrm{~S} \quad 0 \quad 30 \mathrm{~N} 60 \mathrm{~N} 90 \mathrm{~N}$

$90 S 60 S 30 S \quad 0 \quad 30 N 60 N 90 N$

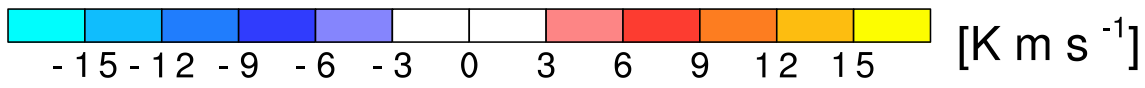

Fig. 4 The same as Fig. 1, except that the time-averaged (top) eddy momentum and (bottom) eddy heat fluxes of the historical K-ACE between 1979-2014 are shown (the contours). The contour intervals for the momentum and heat fluxes are $10 \mathrm{~m}^{-2} \mathrm{~s}^{-2}$ and $2.5 \mathrm{~K} \mathrm{~m} \mathrm{~s}^{-1}$, respectively. The difference between the K-ACE and the ERA-interim is shown by shading
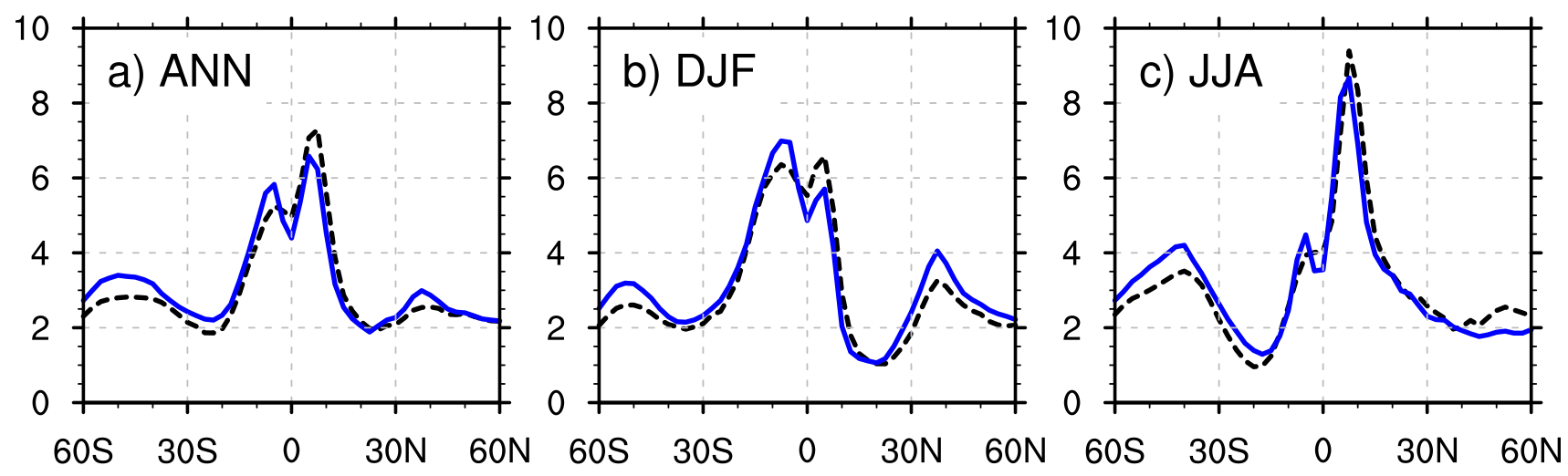

Fig. 5 The same as for Fig. 2, except that the time-averaged zonal mean precipitation $\left(\mathrm{mm} \mathrm{day}^{-1}\right)$ is shown for (a) ANN, (b) DJF, and (c) JJA. The values for the historical K-ACE are shown by the solid blue line, while those for the ERA-interim are shown by the dashed black line 
2015-2100) with that of the historical simulation (years 1979-2014) (Fig. 6). As was reported in previous studies (e.g., Chemke and Polvani 2019), weakening of the HC by approximately $10-15 \%$ can be identified; for the all-season mean, the difference between the SSP5-8.5 and the historical simulations shows negative and positive streamfunction anomalies in the tropics of the $\mathrm{NH}$ and SH, respectively (Fig. 6a). For both DJF and JJA, the weakening of the $\mathrm{HC}$ in the tropics is evident, as indicated by the negative and positive anomalies, respectively (Fig. 6b, c). Interestingly, the anomalies change the sign across the tropopause near $250 \mathrm{hPa}$, suggesting the HCs vertically stretched in the future, which is consistent with the rise of tropopause height (i.e., annual mean tropopause height between $20^{\circ} \mathrm{S}-20^{\circ} \mathrm{N}$ being approximately $100.5 \mathrm{hPa}$ for the SSP5-8.5, in contrast to that of the historical being $106.8 \mathrm{hPa}$ ). Such a baroclinic structure can also be found from the CMIP6 models (not shown). For the extent, the widening of the HC can be observed from the streamfunction anomalies in the subtropics. For example, the positive anomaly at $30^{\circ} \mathrm{N}$ during DJF suggests a poleward expansion of the NH HC (Fig. 6b); similarly, the negative anomaly at $30^{\circ} \mathrm{S}$ during JJA displays the poleward expansion of the SH HC (Fig. 6c).

The temporal evolution of the $\mathrm{HC}$ weakening under the SSP5-8.5 scenario can be examined through the HC strength measured by the $500-\mathrm{hPa}$ zonal mean streamfunction maximum. In Fig. 7, the HC strengths for three ensemble members of the K-ACE (dashed blue lines) and its ensemble mean (solid blue lines) are compared with those of nine CMIP6 models (black lines) and their multi-model mean (red lines). Overall, weakening can be observed in the K-ACE for both January (top panels in Fig. 7) and July (bottom panels in Fig. 7), and the weakening trend resembles that of the CMIP6 models. For example, during January, the boreal winter $\mathrm{HC}$ in the $\mathrm{NH}$ from the K-ACE simulations shows a weakening with the slope of $-0.75 \times 10^{9} \mathrm{~kg} \mathrm{~s}^{-1}$ decade $^{-1}$ for the entire period, which is comparable to the slope of the CMIP6 $\left(-0.90 \times 10^{9} \mathrm{~kg} \mathrm{~s}^{-1}\right.$ decade $^{-1}$ ) (Fig. 7a). These changes become steeper by the late 2000s. Winter NH HC in the K-ACE has negative trends of $-0.9 \times 10^{9} \mathrm{~kg} \mathrm{~s}^{-1}$ decade $^{-1}$ for 50 years of $1950-2000$. During 2050-2100, the trend is drastically decreased to $-2.94 \times 10^{9} \mathrm{~kg} \mathrm{~s}^{-1}$ decade $^{-1}$. Such a steep trend between 2050-2100 is also seen in CMIP6 $\left(-0.23\right.$ to $-2.96 \times 10^{9} \mathrm{~kg} \mathrm{~s}^{-1}$ decade $^{-1}$ ). For the austral winter $\mathrm{HC}$ in the $\mathrm{SH}$, the weakening in the K-ACE occurs at a rate of $0.47 \times 10^{9} \mathrm{~kg} \mathrm{~s}^{-1}$ decade $^{-1}$, while it occurs at $0.50 \times 10^{9} \mathrm{~kg} \mathrm{~s}^{-1}$ decade $^{-1}$ in CMIP6 (Fig. 7d). For the NH summer and SH summer HCs, a weakening trend can be observed in both the K-ACE and the CMIP6 (Fig. 7b, c). Like the boreal winter NH HC, the trend in the SH winter HC has steepened from $0.23 \times 10^{9} \mathrm{~kg} \mathrm{~s}^{-1}$ decade $^{-1}$ for $1950-2000$ to $1.81 \times 10^{9} \mathrm{~kg} \mathrm{~s}^{-1}$ decade $^{-1}$ for $2050-2100$.

The widening of the HC in the SSP5-8.5 scenario shows large inter-model variations. Figure 8 exhibits the temporal evolution of the poleward edge of the $\mathrm{HC}$ for the $\mathrm{NH}$ (panel a) and the $\mathrm{SH}$ (panel b). Note that the 24-year running mean is applied to the poleward latitude of the streamfunction sign reversal, which is computed from the annual mean zonal mean streamfunction at $500 \mathrm{hPa}$. The NH HC edge in K-ACE (Fig. 8a) is projected to expand from approximately $28.5^{\circ} \mathrm{N}$ to $29.4^{\circ} \mathrm{N}$ in the second half of the twenty-first century (blue line in Fig. 8). This is similar to the multi-model mean of the CMIP6, which shows an expansion from approximately $28.6^{\circ} \mathrm{N}$ to $29.6^{\circ} \mathrm{N}$ (red). An expansion of the $\mathrm{HC}$ can also be seen in the SH (Fig. 8b). However, for the $\mathrm{K}-\mathrm{ACE}$, the expansion ranges from near $30.5^{\circ} \mathrm{S}$ to $33.4^{\circ} \mathrm{S}$ (blue line), substantially exceeding the projected range obtained using the CMIP6 multi-model mean, which ranges from near $30.4^{\circ} \mathrm{S}$ to $32.3^{\circ} \mathrm{S}$ (red line). The widening trend increases from $0.04^{\circ}$

MPSI: KACE SSP (2015-2100) - hist (1979-2014)

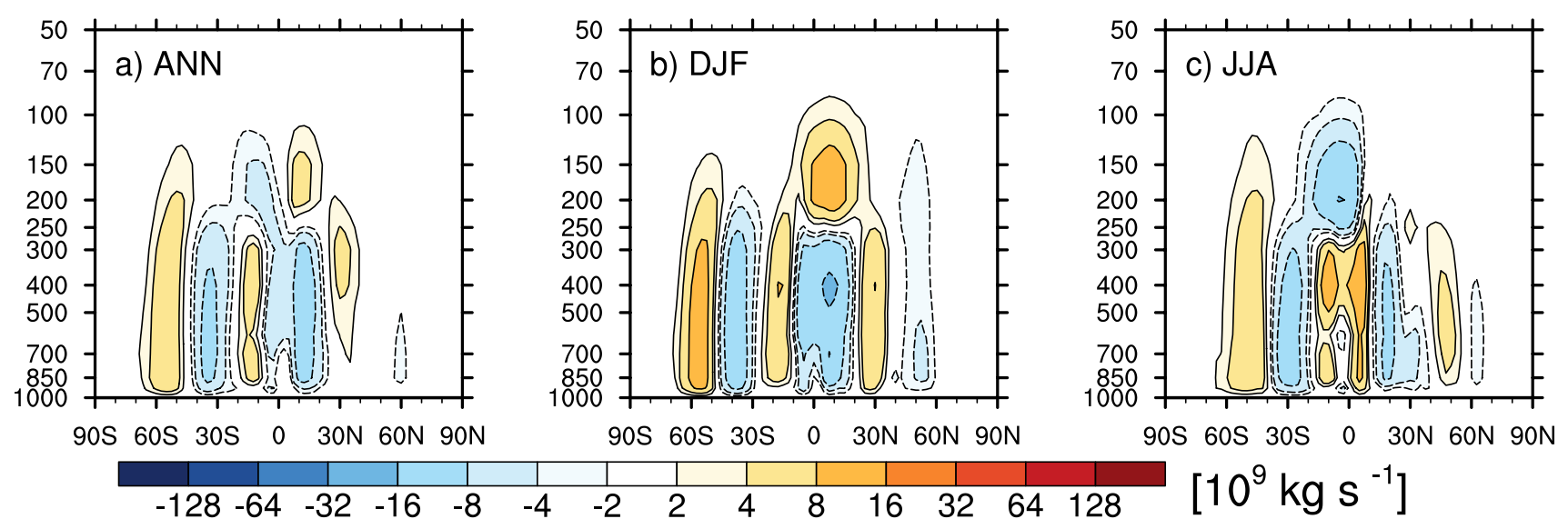

Fig. 6 The difference in zonal mean meridional streamfunction $\left(10^{9} \mathrm{~kg} \mathrm{~s}^{-1}\right)$ obtained by subtracting the values of the SSP5-8.5 run (2015-2100) from the current climate (1979-2014) of K-ACE and time-averaged for (a) ANN, (b) DJF, and (c) JJA 

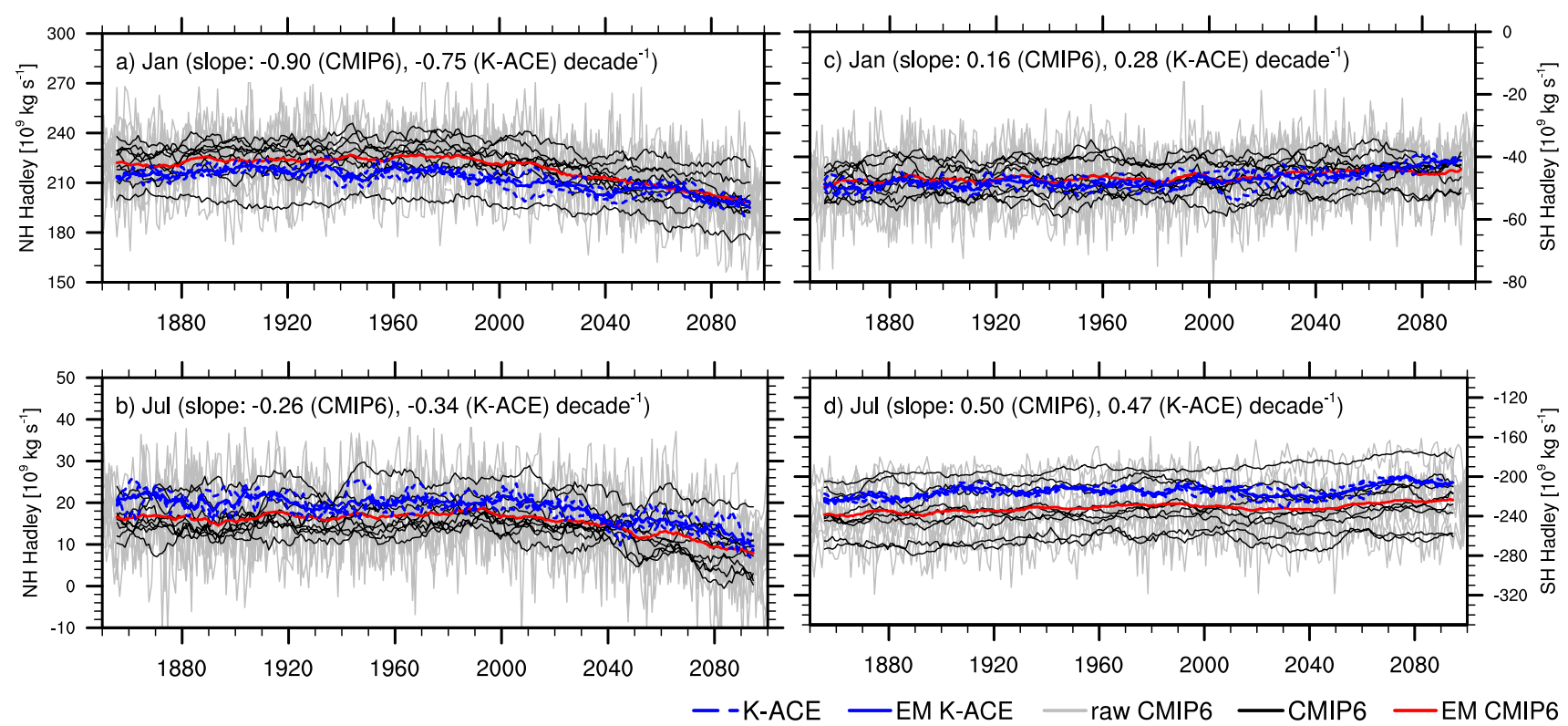

Fig. 7 The NH HC strength shown by the maximum values of the zonal mean meridional streamfunction $\bar{\Psi}$ at $500 \mathrm{hPa}$ (a) between $5^{\circ} \mathrm{S}-30^{\circ} \mathrm{N}$ for January and (b) between $30^{\circ} \mathrm{S}-5^{\circ} \mathrm{N}$ for July. Similarly, the $\mathrm{SH} \mathrm{HC}$ strength is shown by the minimum values (c) between $30^{\circ} \mathrm{S}-5^{\circ} \mathrm{N}$ for January and (b) between $5^{\circ} \mathrm{S}-30^{\circ} \mathrm{N}$ for July. The values for the three ensemble members of the K-ACE are shown by the dashed blue line, while the ensemble mean (EM K-ACE) is shown by the solid blue line. The results for the nine CMIP6 models are shown by the black line, while their multi-model mean (EM CMIP6) is shown by the red line. To investigate long-term changes in the strength time series, the 12-year running average is applied to all time series, except for the original CMIP6 results, by the gray line. The unit for the streamfunction is shown in $10^{9} \mathrm{~kg} \mathrm{~s}^{-1}$. The linear trend for the K-ACE ensemble mean and CMIP6 multi-model mean is denoted in each panel with units of $10^{9} \mathrm{~kg} \mathrm{~s}^{-1}$ decade $^{-1}$

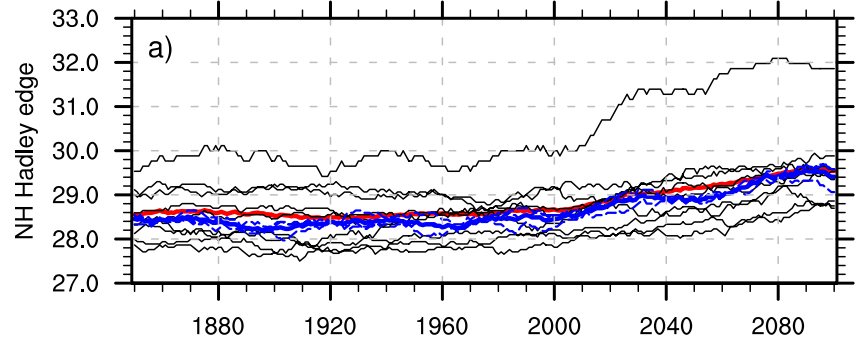

Fig. 8 The Hadley cell edge measured by the latitude of the sign reversal in the annual mean zonal mean streamfunction shown for (a) the NH HC and (b) the SH HC. To remove short-time scale noise, the 24-year running mean is applied. Blue dashed lines indicate the val-

$\left(0.12^{\circ}\right)$ decade $^{-1}$ of years $1950-2000$ to $0.14^{\circ}\left(0.24^{\circ}\right)$ decade $^{-1}$ of years 2050-2100 in NH (SH) HC.

Interestingly, the models that share similar component models with the K-ACE all show extensive widening of the SH HC in the SSP5-8.5 scenario. Those models are the UKESM, the HadGEM3-GC31-LL, and the ACCESSCM2/ESM1, and they are shown by the thin black lines in Fig. 8b. The difference between the K-ACE and the HadGEM3-GC31-LL is the ocean model (i.e., MOM4 vs. NEMO), while it is the land model for the ACCESSCM2/ESM1. The UKESM differs by the ocean model, in

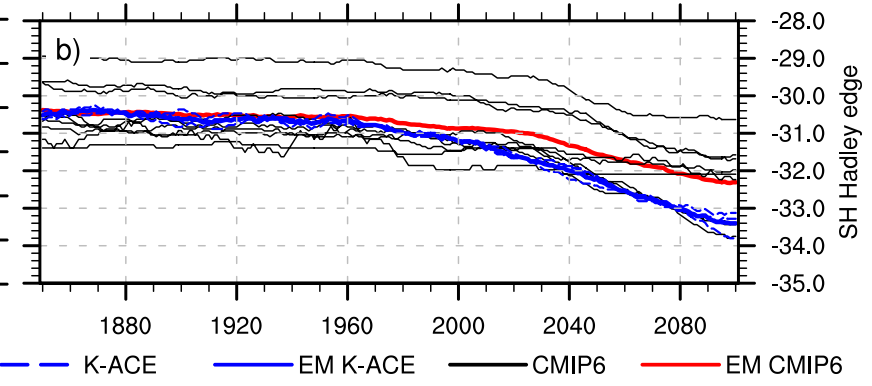

ues of the three ensemble members of the K-ACE, and their ensemble mean is illustrated by the blue solid line. The results for the CMIP6 models and their multi-model mean are shown by black and red lines, respectively

addition to comprehensive treatment in carbon cycles and atmospheric chemistry. Although beyond the scope of this study, it would be an interesting question to study why these family models project substantial widening in the SSP5-8.5 scenario. If including all these models, we find that the HC expansion range obtained using the K-ACE still resides within the multi-model spread of the CMIP6 (black lines).

To identify regions where the amplified widening of the K-ACE SH HC takes place, we analyze the regional HC that is defined for each longitude. Figure 9 presents the meridional streamfunction for the historical simulations (years 1979-2014; 


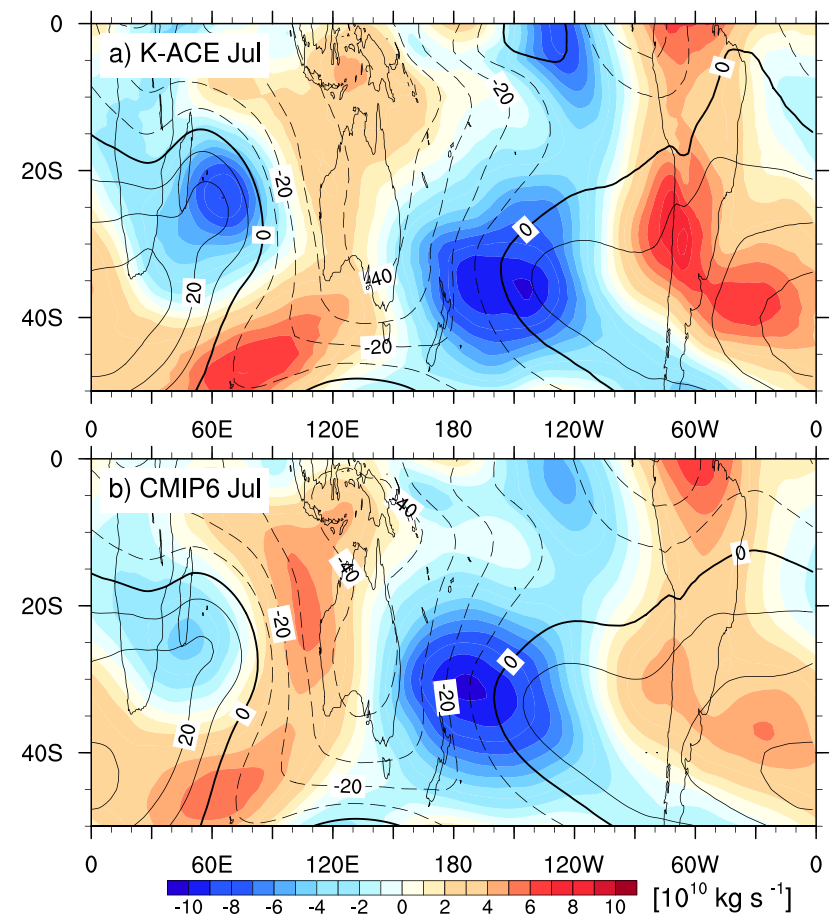

Fig. 9 The time mean meridional streamfunction at $500 \mathrm{hPa}$, defined by the divergent wind of the historical simulation (July in 1979-2014) using Eq. (2), is shown by the contour for the (a) K-ACE and (b) CMIP6. The contour interval is $10 \mathrm{~kg} \mathrm{~s}^{-1}$. Positive (negative) values are indicated by solid (dashed) contours, and the thick black contours show zero values. The difference between the historical and SSP5-8.5 scenario simulations (July in 2015-2100) are show by shading

contours) and its changes in the SSP5-8.5 scenario simulations (years 2015-2100; shaded). Note that the regional HC extents are defined by the latitude at which the meridional streamfunction based on the divergent horizontal wind (i.e., Eq. (2)) changes its sign (thick black contour in Fig. 9). The strong SH HC is located over $80^{\circ} \mathrm{E}-150^{\circ} \mathrm{W}$, and we can discern that its edge is placed south of $50^{\circ} \mathrm{S}$ in several regions, which also notes that it is hard to define the edge for each longitude. However, the strong negative anomaly is shown in the Pacific Ocean near $35^{\circ} \mathrm{S}, 150^{\circ} \mathrm{W}$ for both K-ACE and CMIP6 (Fig. 9a, b, respectively), indicating that the expansion for the July SH HC primarily occur in the Pacific. However, the negative anomaly of the K-ACE is located further southward compared to that of the CMIP6 multi-model mean. In addition, the negative anomaly over the Indian Ocean near $20^{\circ} \mathrm{S}$, $60^{\circ} \mathrm{E}$ is much stronger in the K-ACE than in the CMIP6 models, which contributes to the amplified widening in the K-ACE.

\section{Discussion and Conclusions}

In this study, we evaluated the $\mathrm{HC}$ in the historical and SSP5-8.5 scenario climate simulations using the K-ACE climate model. Overall, the K-ACE presented a reasonable performance in terms of the $\mathrm{HC}$ strength and extent, as well as HC seasonality and future projection. However, several features were found in the K-ACE compared to reanalysis data and simulations by nine CMIP6 models:

- In the historical simulations, the K-ACE generates an $\mathrm{NH}$ HC that is shifted slightly southward, by $1-2^{\circ}$, for both its northern and southern extent, despite its reasonable strength.

- In the historical simulations, the SH HC strength is underestimated by approximately $20 \%$, most pronouncedly during JJA.

- The biases in the HC extent and strength are consistent with the biases in the eddy momentum flux, which shows anomalous convergence near $5^{\circ} \mathrm{N}$, and in the precipitation rate, which exhibits a weaker intensity in the ITCZ compared to observations.

- In the SSP5-8.5 scenario simulations, the weakening and widening of the $\mathrm{HC}$ are projected by the K-ACE. Compared to the CMIP6 models, the widening for the $\mathrm{SH} \mathrm{HC}$ is higher by $1-2^{\circ}$ in the second half of the twenty-first century.

- The overestimated widening in the wintertime SH HC of the $\mathrm{K}-\mathrm{ACE}$ occurs primarily over the Indian and Pacific oceans.

However, our analysis using the diagnostic equation has a limitation, in that the contribution from each term to the $\mathrm{HC}$ formation is not computed quantitatively, although the connection between the $\mathrm{HC}$ bias and the eddy flux and precipitation bias is identified. The relative contribution of each term can be examined by solving the Laplacian equation, which requires performing extensive sensitivity tests on the boundary conditions when constructing the inverse Laplacian. We plan to investigate this problem in our follow-up study.

Acknowledgements This research was supported by the National Research Foundation of Korea (NRF) through grants NRF2018R1A6A1A08025520 and NRF-2019R1C1C1003161. Work of the NIMS/KMA authors was performed under the auspices of the Korea Meteorological Administration Research and Development Program "Development and Assessment of Climate Change Scenarios (KMA2018-00321)."

\section{Declarations}

Conflict of Interest The authors declare that they have no conflict of interest.

Open Access This article is licensed under a Creative Commons Attribution 4.0 International License, which permits use, sharing, adaptation, distribution and reproduction in any medium or format, as long as you give appropriate credit to the original author(s) and the source, provide a link to the Creative Commons licence, and indicate if changes were made. The images or other third party material in this article are included in the article's Creative Commons licence, unless indicated otherwise in a credit line to the material. If material is not included in 
the article's Creative Commons licence and your intended use is not permitted by statutory regulation or exceeds the permitted use, you will need to obtain permission directly from the copyright holder. To view a copy of this licence, visit http://creativecommons.org/licenses/by/4.0/.

\section{References}

Allen, R.J., Ajoku, O.: Future aerosol reductions and widening of the northern tropical belt. J. Geophys. Res. 121, 6765-6786 (2016)

Best, M.J., Pryor, M., Clark, D.B., Rooney, G.G., Essery, R.L.H., Ménard, C.B., Edwards, J.M., Hendry, M.A., Porson, A., Gedney, N., Mercado, L.M., Sitch, S., Blyth, E., Boucher, O., Cox, P.M., Grimmond, C.S.B., Harding, R.J.: The Joint UK Land Environment Simulator (JULES), model description-Part 1: energy and water fluxes. Geosci. Model Dev. 4, 677-699 (2011)

Bindoff, N.L., Stott, P.A., AchutaRao, K.M., Allen, M.R., Gillett, N., Gutzler, D., Hansingo, K., Hegerl, G., Hu, Y., Jain, S., Mokhov, I.I., Overland, J., Perlwitz, J., Sebbari, R., Zhang, X.: Detection and attribution of climate change: from global to regional, 867952. Cambridge University Press (2013)

Cai, W., Cowan, T.: Southeast Australia autumn rainfall reduction: A climate-change-induced poleward shift of ocean-atmosphere circulation. J. Climate 26, 189-205 (2013)

Chemke, R., Polvani, L.M.: Opposite tropical circulation trends in climate models and in reanalyses. Nature Geosci. 12, 528-532 (2019)

Choi, J., Son, S.-W., Park, R.J.: Aerosol versus greenhouse gas impacts on Southern Hemisphere general circulation changes. Climate Dyn. 52, 4127-4142 (2019)

Dee, D.P., Uppala, S.M., Simmons, A.J., Berrisford, P., Poli, P., Kobayashi, S., Andrae, U., Balmaseda, M.A., Balsamo, G., Bauer, P., Bechtold, P., Beljaars, A.C.M., van de Berg, L., Bidlot, J., Bormann, N., Delsol, C., Dragani, R., Fuentes, M., Geer, A.J., Haimberger, L., Healy, S.B., Hersbach, H., Hólm, E.V., Isaksen, L., Kållberg, P., Köhler, M., Matricardi, M., McNally, A.P., MongeSanz, B.M., Morcrette, J.-J., Park, B.-K., Peubey, C., de Rosnay, P., Tavolato, C., Thépaut, J.-N., Vitart, F.: The ERA-Interim reanalysis: configuration and performance of the data assimilation system. Quart. J. Roy. Meteor. Soc. 137, 553-597 (2011)

Dima, I.M., Wallace, J.M.: On the Seasonality of the Hadley Cell. J. Atmos. Sci. 60, 1522-1527 (2003)

Fu, R., Yin, L., Li, W., Arias, P.A., Dickinson, R.E., Huang, L., Chakraborty, S., Fernandes, K., Liebmann, B., Fisher, R., Myneni, R.B.: Increased dry-season length over southern Amazonia in recent decades and its implication for future climate projection. Proc. Natl. Acad. Sci. USA 110, 18110-18115 (2013)

Griffies, S., Harrison, M., Pacanowski, R., Rosati, A.: GFDL Ocean Group Technical Report No. 5. A technical guide to MOM 4, NOAA/Geophysical Fluid Dynamics Laboratory, 342 (2004)

Grise, K. M., and Coauthors: Recent Tropical Expansion: Natural Variability or Forced Response? J. Climate, 32, 1551-1571. (2019). https:doi.org/10.1175/jcli-d-18-0444.1

Grise, K., Davis, S.: Hadley cell expansion in CMIP6 models. Atmos. Chem. Phys. 20, 5249-5268 (2020)

Holton, J. R., Hakim, G. J.: Chapter 10 - The General Circulation. An Introduction to Dynamic Meteorology (Fifth Edition), J. R. Holton, and G. J. Hakim, Eds., Academic Press, 325-375 (2013)

$\mathrm{Hu}, \mathrm{Y} ., \mathrm{Fu}, \mathrm{Q} .:$ Observed poleward expansion of the Hadley circulation since 1979. Atmos. Chem. Phys. 7, 5229-5236 (2007)

$\mathrm{Hu}$, Y., Huang, H., Zhou, C.: Widening and weakening of the Hadley circulation under global warming. Sci. Bull 63, 640-644 (2018)

Hunke, E., Lipscomb, W., Turner, A., Jeffery, N., Elliott, S.: CICE: The Los Alamos Sea ice Model Documentation and Software User's Manual Version 5 (Tech. Rep. LA-CC-06-012). Los Alamos: Los Alamos National Laboratory (2015)
Kim, Y.-H., Min, S.-K., Son, S.-W., Choi, J.: Attribution of the local Hadley cell widening in the Southern Hemisphere. Geophys. Res. Lett. 44, 1015-1024 (2017). https://doi.org/10.1002/2016GL072353

Lee, J., Kim, J., Sun, M.-A., Kim, B.-H., Moon, H., Sung, H.M., Kim, J., Byun, Y.-H.: Evaluation of the Korea Meteorological Administration Advanced Community Earth-System model (K-ACE). Asis-Pacific J. Atmos. Sci 56, 381-395 (2020)

Liu, J., Song, M., Hu, Y., Ren, X.: Changes in the strength and width of the Hadley Circulation since 1871. Clim. Past 8, 1169-1175 (2012)

Lu, J., Vecchi, G.A., Reichler, T.: Expansion of the Hadley cell under global warming. Geophys. Res. Lett. 34, L06805 (2007)

Nguyen, H., Evans, A., Lucas, C., Smith, I., Timbal, B.: The hadley circulation in reanalyses: climatology, variability, and change. J. Climate 26, 3357-3376 (2013)

O’Neill, B.C., Tebaldi, C., van Vuuren, D.P., Eyring, V., Friedlingstein, P., Hurtt, G., Knutti, R., Kriegler, E., Lamarque, J.F., Lowe, J., Meehl, G.A., Moss, R., Riahi, K., Sanderson, B.M.: The Scenario Model Intercomparison Project (ScenarioMIP) for CMIP6. Geosci. Model Dev. 9, 3461-3482 (2016)

Rollings, M., Merlis, T.M.: The observed relationship between Pacific SST variability and Hadley cell extent trends in reanalyses. J. Climate, 1-49 (2021)

Schwendike, J., Govekar, P., Reeder, M.J., Wardle, R., Berry, G.J., Jakob, C.: Local partitioning of the overturning circulation in the tropics and the connection to the Hadley and Walker circulations. J. Geophys. Res. 119, 1322-1339 (2014)

Son, S.-W., Gerber, E.P., Perlwitz, J., Polvani, L.M., Gillett, N.P., Seo, K.-H., Eyring, V., Shepherd, T.G., Waugh, D., Akiyoshi, H., Austin, J., Baumgaertner, A., Bekki, S., Braesicke, P., Brühl, C., Butchart, N., Chipperfield, M.P., Cugnet, D., Dameris, M., Dhomse, S., Frith, S., Garny, H., Garcia, R., Hardiman, S.C., Jöckel, P., Lamarque, J.F., Mancini, E., Marchand, M., Michou, M., Nakamura, T., Morgenstern, O., Pitari, G., Plummer, D.A., Pyle, J., Rozanov, E., Scinocca, J. F., Shibata, K., Smale, D., Teyssèdre, H., Tian, W., Yamashita, Y.:. Impact of stratospheric ozone on Southern Hemisphere circulation change: a multimodel assessment. J. Geophys. Res. 115, D00M07 (2010)

Staten, P.W., Grise, K.M., Davis, S.M., Karnauskas, K., Davis, N.: Regional widening of tropical overturning: Forced change, natural variability, and recent trends. J Geophys. Res. Atmos. 124, 6104-6119 (2019)

Sung, H. M., Kim, J., Shim, S., Seo, J.-b., Kwon, S.-H., Sun, M.-A., Moon, H. Lee, J.-H., Lim, Y.-J., Boo, K.-O., Kim, Y., Lee, J, Lee, J., Kim, J., Marzin, C., Byun, Y.-H.: Climate Change Projection in the Twenty-First Century Simulated by NIMS-KMA CMIP6 Model Based on New GHGs Concentration Pathways. Asis-Pacific J. Atmos. Sci 1-12 (2021)

Tao, L., Hu, Y., Liu, J.: Anthropogenic forcing on the Hadley circulation in CMIP5 simulations. Climate Dyn. 46, 3337-3350 (2016)

Tian, B., Dong, X.: The double-ITCZ bias in CMIP3, CMIP5, and CMIP6 models based on annual mean precipitation. Geophys. Res. Lett. 47, e2020GL087232 (2020)

Walters, D., Baran, A.J., Boutle, I., Brooks, M., Earnshaw, P., Edwards, J., Furtado, K., Hill, P., Lock, A., Manners, J.: The Met Office Unified Model global atmosphere 7.0/7.1 and JULES global land 7.0 configurations. Geosci. Model Dev. 12, 1909-1963 (2019)

Wilcox, L. J., Charlton-Perez, A.J., Gray, L. J.: Trends in Austral jet position in ensembles of high- and low-top CMIP5 models. J. Geophys. Res. 117 (2012)

Zhou, C., Lu, J., Hu, Y., Zelinka, M.D.: Responses of the Hadley Circulation to Regional Sea Surface Temperature Changes. J. Climate 33, 429-441 (2020)

Publisher's Note Springer Nature remains neutral with regard to jurisdictional claims in published maps and institutional affiliations. 